\title{
TEM Characterization of Crept and Irradiated Nano-structured Ferritic Alloys
}

\author{
J. Bentley, ${ }^{*}$ D.T. Hoelzer, ${ }^{*}$ J.T. Busby, ${ }^{*}$ A.G. Certain, ${ }^{\S}$ T.R. Allen,${ }^{\S}$ D. Kaoumi, ${ }^{\ddagger}$ A.T. Motta, ${ }^{\ddagger}$ and M.A. Kirk ${ }^{\dagger}$ \\ *Materials Science \& Technology Div., Oak Ridge National Laboratory, Oak Ridge, TN 37831 \\ ${ }^{\S}$ Material Science Program, University of Wisconsin, Madison, WI 53706 \\ tDept. of Mech. \& Nuclear Eng., Pennsylvania State University, University Park, PA 16802 \\ ${ }^{\dagger}$ Materials Science Division, Argonne National Laboratory, Argonne, IL 60439
}

The past ten years or so have seen the development of an exciting new class of mechanically alloyed (MA) nano-structured ferritic alloys (NFA) with outstanding mechanical properties that are mostly due to the presence of high concentrations $\left(>10^{23} \mathrm{~m}^{-3}\right)$ of $\mathrm{Ti}-, \mathrm{Y}-$, and O-enriched nano-clusters (NC). Because NC may promote point defect recombination and trap transmutation-produced He in small clusters, NFA have the potential to be highly resistant to radiation damage in fission and fusion environments [1,2], and thus are being characterized following neutron and ion irradiation. Energy-filtered transmission electron microscopy (EFTEM) performed at $300 \mathrm{kV}$ on a LaB Philips CM30 equipped with a Gatan imaging filter (GIF) has been especially beneficial for imaging NC. In particular, Fe-M jump-ratio images produced from component images recorded with $10-\mathrm{eV}$ slits at energy losses of 46 and $62 \mathrm{eV}$ reliably reveal $\mathrm{NC}$ in dark contrast. Such images are insensitive to surface oxide films or modest surface contamination and for sufficiently thin regions $(<50 \mathrm{~nm}) 2-\mathrm{nm}$ diameter $\mathrm{NC}$ are visible [3]. Additional EFTEM elemental mapping (e.g. O, Ti-L ${ }_{23}, \mathrm{Cr}_{-} \mathrm{L}_{23}$ ) has also been usefully applied to NFA, and focused-ion-beam (FIB) lift-out specimens have been used to good advantage [2]. Fabrication of an Fe-14.2wt.\%Cr-1.95\%W-0.22\%Ti- $0.25 \% \mathrm{Y}_{2} \mathrm{O}_{3}$ NFA, designated 14YWT, has been described elsewhere, as have the contributions of TEM to help optimize material processing parameters $[3,4]$. It was also previously shown that NC in $14 \mathrm{YWT}$ are not detectably changed by tensile testing at 25 and $700^{\circ} \mathrm{C}$ with total strains of up to $39 \%$ [5] and that in MA957 (an INCO-patented Fe-14wt\%Cr-1\%Ti-0.3\%Mo- $0.27 \% \mathrm{Y}_{2} \mathrm{O}_{3} \mathrm{NFA}$ ) neutron irradiated at $500^{\circ} \mathrm{C}$ to 9 displacements per atom (dpa) and with $\sim 380$ appm He, the diameter $(\sim 3 \mathrm{~nm})$ and concentration $\left(\sim 4 \times 10^{23} \mathrm{~m}^{-3}\right)$ of the NC differ little from those of unirradiated MA957 [1,2].

The NC in MA957 also appear to be unchanged after creep testing in air for a remarkable 38,555 $\mathrm{h}$ at $800^{\circ} \mathrm{C}$ and $100 \mathrm{MPa}$ (Fig. 1). Cavities of $>1 \mu \mathrm{m}$ diameter present in the crept specimen may have formed from the release of gases entrained during the original material processing (a potential problem for all MA materials) and may have initiated specimen rupture after a uniform strain of $<0.4 \%$. In TEM specimens prepared by electropolishing these cavities caused premature perforation with little or no thin regions, so it was necessary to use FIB lift-out specimens. A Japanese $9 \mathrm{Cr}$ oxide-dispersion-strengthened (ODS) steel (Fe-8.6wt.\%Cr-1.95\%W-0.23\%Ti-0.27\% Y-0.14\%O) was irradiated at $525^{\circ} \mathrm{C}$ with $2.6 \mathrm{MeV}$ protons at $\sim 5 \times 10^{-6} \mathrm{dpa} / \mathrm{s}$ to $1 \mathrm{dpa}$ at the University of Wisconsin [6]. EFTEM results showed that the mean diameter $(\sim 3.2 \mathrm{~nm})$ and concentration $\left(\sim 1 \times 10^{23} \mathrm{~m}^{-3}\right)$ of NC were approximately the same in irradiated and unirradiated material. However, the NC were heterogeneously distributed with factors of $>2.5$ (unirradiated) and $>5$ (irradiated) variation in the mean concentration over 6 mapped regions in each sample and with a $\sim 2$-fold variation in mean diameter for the same regions (Fig. 2). Interestingly, EFTEM also indicated that NC were enriched in C. Specimens of Japanese 9Cr ODS steel, a French (CEA) 18Cr ODS alloy, and MA957 have been ion irradiated in situ at the IVEM-Tandem Facility of Argonne National Laboratory (ANL) at 25 and $500^{\circ} \mathrm{C}$ to doses up to $100 \mathrm{dpa}$. One aspect of the research on these specimens is to determine the fate of NC by ex-situ EFTEM performed at ORNL. Preliminary results have shown NC present in $9 \mathrm{Cr}$ ODS steel after irradiation with $300 \mathrm{keV} \mathrm{Fe}$ ions to $12 \mathrm{dpa}$ at $25^{\circ} \mathrm{C}$ and $18 \mathrm{dpa}$ at $500^{\circ} \mathrm{C}$.

The highly heterogeneous distributions of NC in NFA lead to difficulties in studying the effects of irradiation, unless radical changes in NC size or concentration are induced. The dominance of TEM specimen surfaces as point defect sinks notwithstanding, one possible way to study more subtle effects of irradiation on NC (and of NC on the development of damage structure), is by in-situ ion irradiation, ideally in a TEM with EFTEM capabilities, such as at the JANNuS facility in France [7]. 
Experiments are in progress using an alternative approach that involves characterization, including EFTEM imaging of NC at ORNL, of selected regions of 14YWT TEM specimens before and after in-situ ion irradiation at ANL. The vacuum quality at the specimen during elevated-temperature insitu irradiation is of great importance because of potential interstitial-impurity (e.g. $\mathrm{O}, \mathrm{C}$ or N) pickup or even oxidation, especially since NC imaging by EFTEM is limited to such thin regions. Characterization of NC in 14YWT by EFTEM before and after in-situ annealing at $500^{\circ} \mathrm{C}$ for $1 \mathrm{~h}$ (without irradiation) in the unmodified, ion-pumped column of a CM30 at a pressure of $\sim 2 \times 10^{-7}$ Torr revealed that although some NC survived, quite severe specimen degradation also occurred [8].

1. T. Yamamoto et al., J Nucl. Mater. 367-370 (2007) 399.

2. J. Bentley et al., Microsc. Microanal. 13(Suppl 2) (2007) 1072.

3. J. Bentley et al., Microsc. Microanal. 10(Suppl 2) (2004) 662.

4. D.T. Hoelzer et al., J Nucl. Mater. 367-370 (2007) 166.

5. J. Bentley and D.T. Hoelzer, Microsc. Microanal. 14(Suppl 2) (2008) 1416.

6. A.G. Certain et al., to be submitted to J Nucl. Mater. (2009).

7. http://jannus.in2p3.fr/spip.php

8. Thanks to P. Baldo (ANL), L.T. Gibson, D.W. Coffey, and K. Thomas (ORNL) for technical assistance. Research at ORNL supported by the Laboratory Directed Research and Development Program of ORNL, by the Office of Fusion Energy Sciences, by the Office of Nuclear Energy, Science and Technology through I-NERI 2001-007-F and the Advanced Fuel Cycle Initiative, by the Division of Materials Sciences and Engineering, Office of Basic Energy Sciences, and the ORNL SHaRE User Facility, Division of Scientific User Facilities, Office of Basic Energy Sciences, U.S. Department of Energy. Additional research support was provided by a Nuclear Energy Research Initiative Consortium (NERI-C) Award from the U.S. Department of Energy. The IVEM-Tandem Facility (within the Electron Microscopy Center at ANL) is supported by the U.S. DOE Office of Science and operated under contract no. DE-AC02-06CH11357 by U Chicago Argonne, LLC.

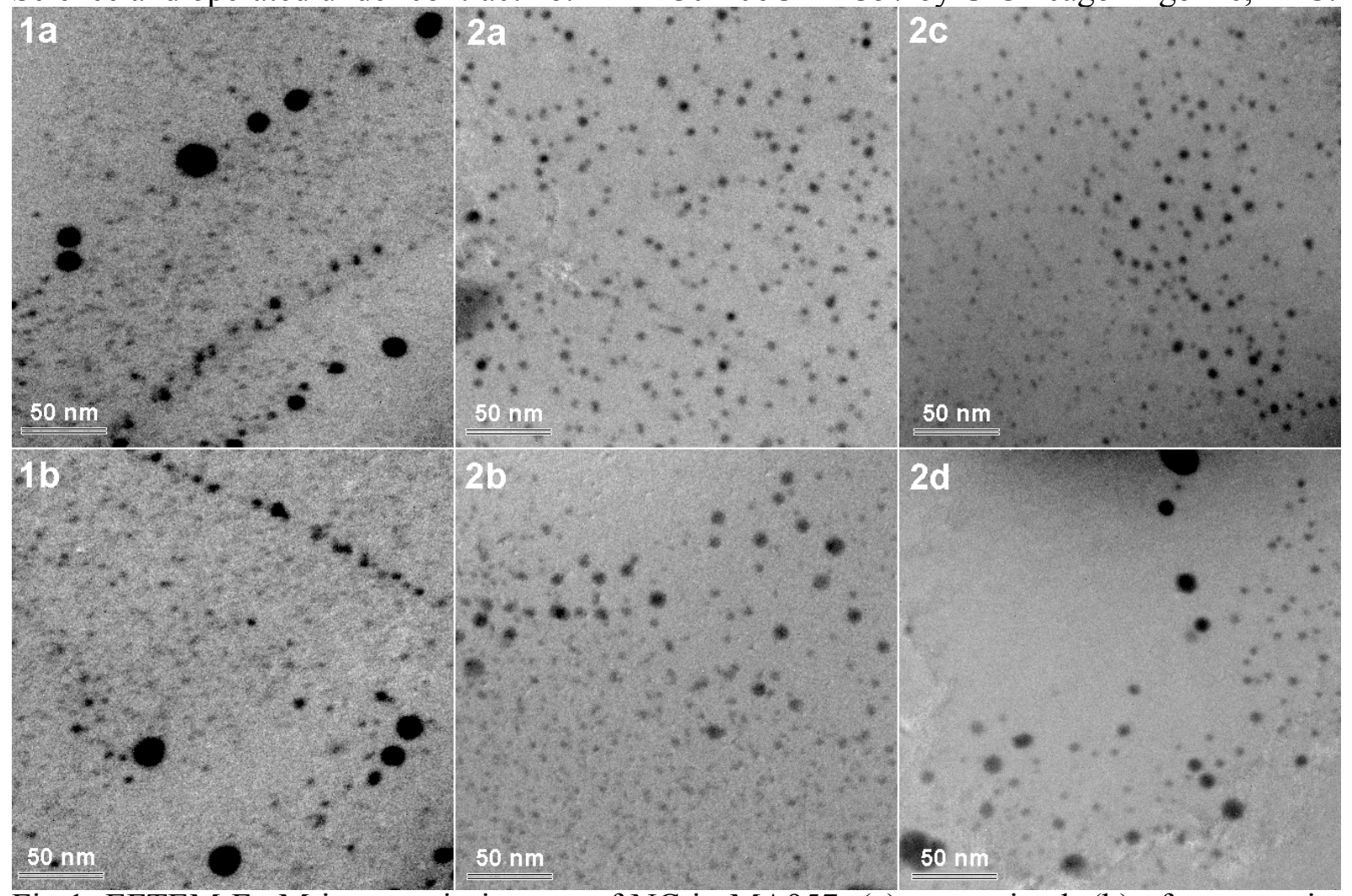

Fig.1. EFTEM Fe-M jump-ratio images of NC in MA957: (a) as received; (b) after creep in air for $38,555 \mathrm{~h}$ at $800^{\circ} \mathrm{C}$ and $100 \mathrm{MPa}$. Fig. 2. EFTEM Fe-M jump-ratio images of NC in a 9Cr ODS steel (a,b) unirradiated; (c,d) after irradiation with $2.6 \mathrm{MeV}$ protons to $1 \mathrm{dpa}$ at $525^{\circ} \mathrm{C}$. 